\title{
Intelligent Agents in Learning Environment ABDITS
}

\author{
Shweta Mahlawat \\ Research Student \\ Dept. of Computer Science \\ Banasthali University, Raj
}

\author{
O.P. Rishi \\ Associate Professor \\ Dept. of Computer Science \\ University of Kota, Raj, India
}

\author{
Praveen Dhyani \\ Professor \\ Ph.D. Executive Director \\ Banasthali University, Jaipur
}

\begin{abstract}
In this paper, a multiagent system i.e. named ABDITS (Agent Based Distributed Intelligent Tutoring System) is presented, which is customizable, dynamic, intelligent and adaptive with Pedagogy view for learners in intelligent schools. This system is an integration of adaptive web-based learning with expert systems as well. A crucial feature of the ABDITS personal agent is that the case based reasoning approach for student modeling. The system will categorize students in step with their skills in processing, perceiving, entering, organizing and understanding the knowledge. Intelligent agents are intended to examine the opportunities to enhance the teaching and to motivate the scholars to be told what they require, in an exceedingly user friendly environment that suits their learning style.
\end{abstract}

\section{Keywords}

ABDITS; FSLSM; CBR; ILS; Habitatpro etc

\section{INTRODUCTION}

The Internet provides associate degree infrastructure that supports unprecedented communication capabilities and opportunities for collaboration. Within the field of education, the Internet permits collaboration between varied domain experts and lecturers in coming up with novel approaches to teaching and co-operation among lecturers who can share instructional material. It offers a massive store of data that can be accessed in an exceedingly structured manner or explored in an unstructured manner, providing opportunities for designing tutoring systems with various education strategies. The liberty and adaptability offered by the Internet will, however, transform associate degree immense waste of time, effort and resources, if the character of instructional processes and the capabilities of instructional technologies don't seem to be adequately thought-about whereas coming up with a tutoring system.

In this paper, a multi agent intelligent system approach (ABDITS) has been developed that aims to boost adaptation options within the USD platform using internet technology. The present USD system is an adaptable platform that permits lecturers to create and manage teaching units for consecutive or free navigation. A teaching unit consists of a group of hypertext markup language pages that contains the informative material. The navigation structure is given by means that of a directed graph found out by the teacher following his/her information criteria. Students may customize their learning surroundings by choosing the operating language and therefore the size, form and position of the icons. The navigation surroundings provides varied tools: to navigate the training contents in an exceedingly radio-controlled or free way (using forward or backward buttons, a contents tree, or a wordbook of terms); to form self assessed, interactive exercises; to speak with student and teacher communities (e-mail, chat); to form bookmarks ; to print out learning contents; to visualize student progress; etc.
The ABDITS multi-agent system models the student by means that of the HabitatPro environment, a tool for contents personalization and market prospecting using case-based reasoning and formal logic AI techniques. The Felder and Silverman Learning style Model (FSLSM) has been used to categorize students consistent with their skills in process, perceiving, entering, organizing and understanding the knowledge. For the initial student classification, a tendency will apply the Index for Learning styles (ILS), a diagnostic instrument that assesses preferences on four dimensions (active/reflective, sensing/intuitive, visual/verbal, and sequential/global) which is an element of the FSLSM model. The aim of student modeling during this system is to retrieve the relevant informative contents (taking into thought media formats, and instructional strategies), navigation tools and navigation strategies for college students with completely different learning designs. Therefore, the USD platform will be used as associate degree adaptation teaching and learning web-site.

The following section describes the most characteristics and performance of the ABDITS system proposed and last section concludes the paper with a summary.

\section{THE ABDITS MULTIAGENT SYSTEM}

The ABDITS system is developed on the FIPA compliant multi agent system using programming languages at completely different stages of the agent's programming. The subsequent properties were specially considered when designing the agents:

- Interactivity: the agent ought to move with its electronic setting once representing the individual or the entity. Throughout this part it should be capable of finishing up differing kinds of communication with different agents, additionally in keeping with the interacting entity. As an example, ABDITS monitoring agents understand student's actions at USD learning setting and consequently they move with the HabitatPro system to fine-tune the student model at an appropriate time.

- Autonomy: the agents ought to be semiautonomous. This means that they do not want a relentless and direct supervising. This feature is crucial for his or her representation tasks however, since there are completely different degrees of autonomy, the agent can forever be underneath the management of the entity or person who it represents. For example, the ABDITS artificial agent knows once and the way to represent any message to the student and once it's to update its content.

- Proactivity: the intelligent agents are proactive. This means that they need goals or specific objectives (i.e. to search out informative contents in graphic media, to select structural navigation tools, etc.) and act consequently and in an autonomous manner to achieve them. 
- Learning: the intelligent agents ought to code knowledge concerning the diagrammatical entity and also the environment wherever they perform their functions. This knowledge is dynamic as a result of it changes with time. The agent should be ready to learn from its environment and from interaction with different agents and incorporate these changes into its data base. ABDITS personal agent learns from student interactions so as to adapt the educational environment to student preferences (perceived by means of change the student's stereotype profile based on learning styles).
The agency and personalization model for the ABDITS environment is shown in Figure 1. Different students (rectangles) move with environs (USD platform) by means that of various agents (circles) that represent them. The agents have a double function: to interact with one another and with the environs on behalf of the student and to filter the data (type and magnificence of didactic contents, navigation tools and navigation techniques) that the scholars receive from different agents and the environs. The agents are individuals (each student has his/her own) and have data concerning the objectives and learning varieties of the scholars that they represent and also are capable of learning from the interactions with the setting.

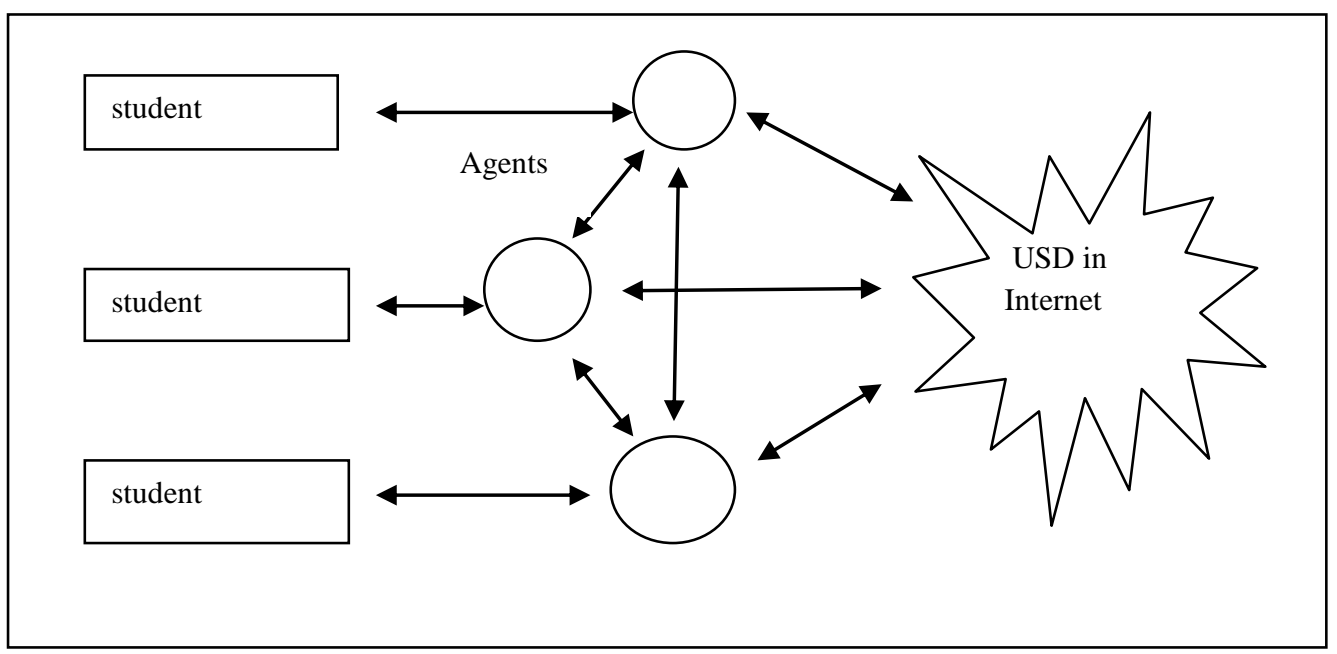

Figure1 ABDITS model of agency and personalization

Figure 2 shows the projected ABDITS architecture that is deep-seated by Profile agent, Evaluation Agent, Test Agent and Exercise Agent at the lower (inner) level and Personal Agent, Teaching Agent and Course Agent at the higher (outer) level. The Personal agent tries to change learning tasks, either permitting the student to program their activities supported examples, or imitating the student's behavior and adapting to that. The Teaching agent, an easy reflective agent that is for its operation uses information for the tasks that the student or the tutor wants it to hold out, additionally as sure events happening in the learning surroundings.

- A warning once a particular acquaintance comes on-line.

- Suggesting the revision of the listing references in some sections of the lesson.
- Suggesting the effecting the interactive exercises proposed once the student get to explicit sections of the lesson.

- Warning if he/she has gone on the far side a particular time of study.

- Reminding the coed with personalized messages at a determined time.

- Within the special case of a professor's message, getting the attention of some students presently connected to the system in order that they may revise some specific sections of the lesson, solve a specific downside or enter the chat area to hold out associate degree on-line discussion. 


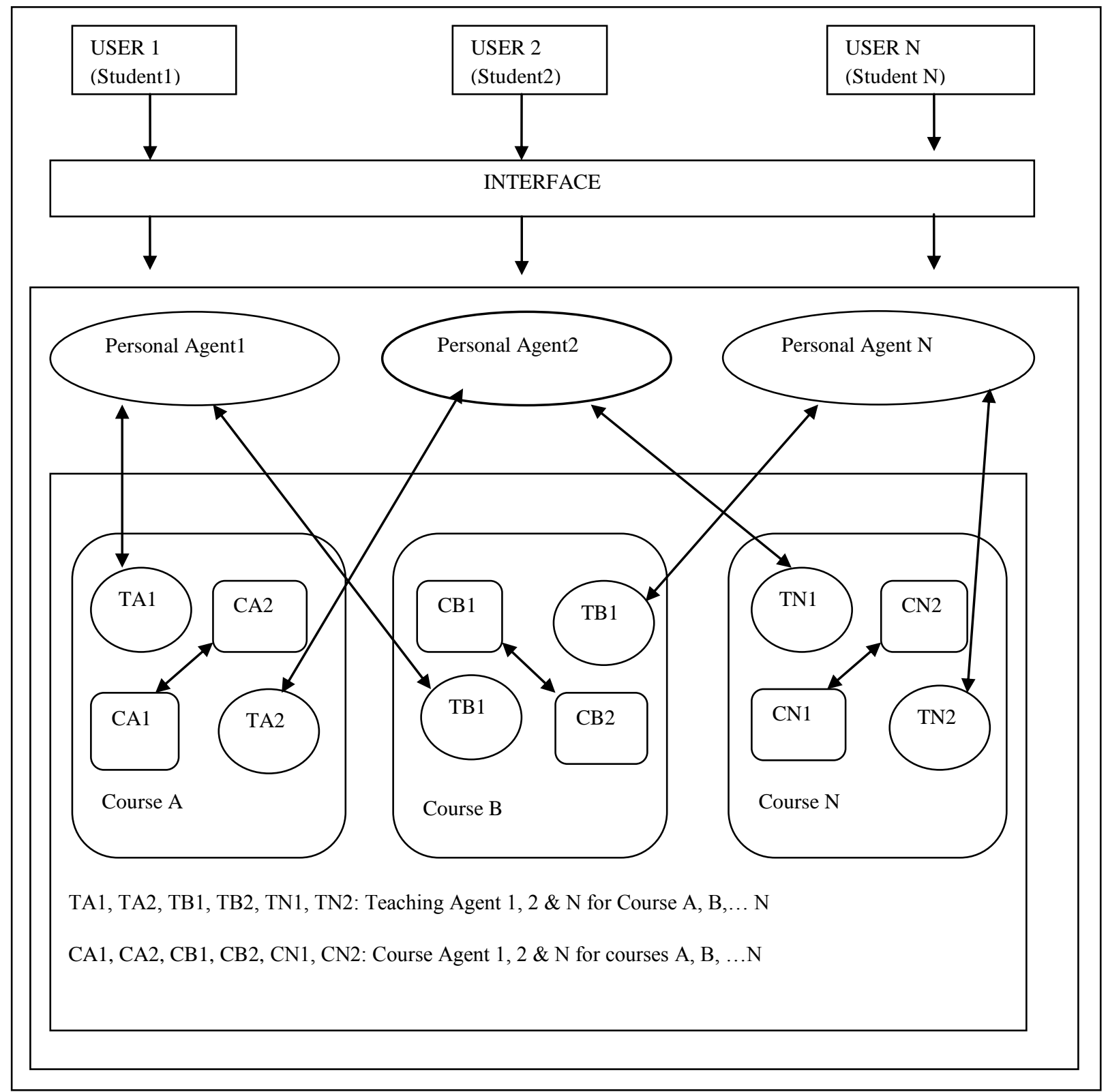

Figure 2: Architecture of ABDITS

The Evaluation agents monitor the student's activities in order to get feedback to their behavior model (on assessment and on interactions).

The Teaching agent is introduced with associate degree animated design (anthropomorphous) within the interface, presenting the messages returning from alternative agents, within the style of suggestions or warnings once the student exhibits special behavior throughout the training activity. As associate degree example, Personal Agent has been presented as an associate degree agent that represents within the user's interface, the messages returning from alternative ABDITS agents appointed to the user. It adopts a satisfying anthropomorphic style following the schematized performance showed at Figure 3.

The Teaching agent organizes the navigation methods by directly interaction with databases and by communicating with the Course agent and therefore the Personal agent.

The Personal agent builds and maintains the student model by suggests that of the HabitatPro setting interaction. The
HabitatPro setting offers to the ABDITS system, info to update a personal agent for every student which will apprehend his/her likes and preferences (subjectivity) and can be able to advocate automatically, appropriate teaching units, navigation techniques and navigation tools. In consequence, this approach can enable the system to be additional competitive because operating with subjectiveness can allow it to acquire information which will be transported and used profitably by any teaching unit or instructive content offered. Thus, the system can supply academic solutions in terms of every demand.

Each user's agent can proactively increase the knowledge that it's regarding his/her student by applying his/ her own ways. It'll be able to make up one's mind the motivation info to the student's wants and to improve the system's performance by using different motivation techniques, cooperative filtering and self criticism.

The HabitatPro system uses Case-Based Reasoning techniques [10] to fine-tune the student's profile in order that gradually it'll mirror additional dependably the coed 
resemblance to his/her learning style. To require the primary student profile (stereotype) supported learning designs, we applied the Index for learning types of the FSLSM model and appointed materials considering the distribution proposed on
Table1 ensuing from adapting experiences from similar approaches [1] and basic characteristics of current teaching materials from the USD setting.

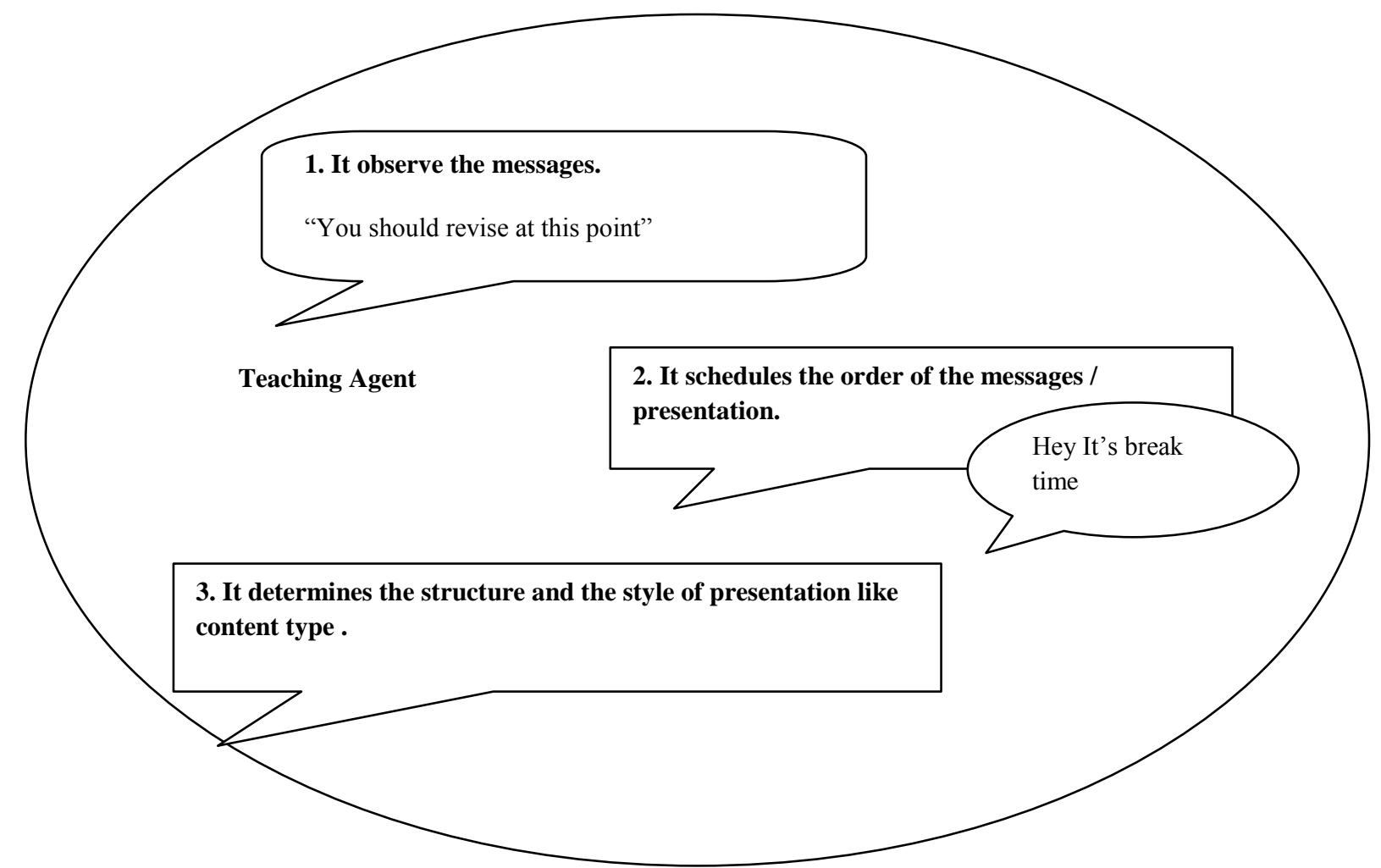

Figure 3: General Representation of the Teaching Agent Performance

Table 1. Hypermedia course components for ABDITS considering Felder learning styles

a. Instructional Strategy

\begin{tabular}{|c|c|c|c|c|c|c|}
\hline & $\begin{array}{l}\text { Lesson } \\
\text { Objectives }\end{array}$ & Case studies & Lectures & $\begin{array}{l}\text { Knowledge } \\
\text { nucleus }\end{array}$ & $\begin{array}{l}\text { Conceptual } \\
\text { maps }\end{array}$ & Synthesis \\
\hline Active & & & & $\sqrt{ }$ & & \\
\hline Reflective & $\sqrt{ }$ & $\sqrt{ }$ & $\sqrt{ }$ & & $\sqrt{ }$ & \\
\hline Sensing & & $\sqrt{ }$ & & & $\sqrt{ }$ & \\
\hline Intuitive & $\sqrt{ }$ & & & & $\sqrt{ }$ & \\
\hline Visual & & $\sqrt{ }$ & & & $\sqrt{ }$ & $\sqrt{ }$ \\
\hline Verbal & $\sqrt{ }$ & & $\sqrt{ }$ & & $\sqrt{ }$ & \\
\hline Sequential & & & & & $\sqrt{ }$ & \\
\hline Global & $\sqrt{ }$ & & & & & $\sqrt{ }$ \\
\hline
\end{tabular}

b. Media format

\begin{tabular}{|c|c|c|c|c|c|c|}
\hline & \multicolumn{2}{|c|}{ Slideshow } & \multicolumn{3}{|c|}{ Media clips } & \multirow[t]{2}{*}{ Lineal Texts } \\
\hline & Text & Multimedia & Graphics & $\begin{array}{l}\text { Digital } \\
\text { movies }\end{array}$ & Audio & \\
\hline Active & & & & & & $\sqrt{ }$ \\
\hline Reflective & $\sqrt{ }$ & & & & & $\sqrt{ }$ \\
\hline Sensing & & $\sqrt{ }$ & $\sqrt{ }$ & $\sqrt{ }$ & $\sqrt{ }$ & $\sqrt{ }$ \\
\hline Intuitive & $\sqrt{ }$ & $\sqrt{ }$ & $\sqrt{ }$ & $\sqrt{ }$ & $\sqrt{ }$ & $\sqrt{ }$ \\
\hline Visual & & $\sqrt{ }$ & $\sqrt{ }$ & $\sqrt{ }$ & & \\
\hline Verbal & $\sqrt{ }$ & & & & $\sqrt{ }$ & $\sqrt{ }$ \\
\hline Sequential & $\sqrt{ }$ & $\sqrt{ }$ & & $\sqrt{ }$ & $\sqrt{ }$ & $\sqrt{ }$ \\
\hline Global & & & $\sqrt{ }$ & $\sqrt{ }$ & & \\
\hline
\end{tabular}


c. Navigation tools

\begin{tabular}{|l|l|l|l|l|l|l|l|l|}
\hline & \multicolumn{2}{|l|}{ Punctuals } & \multicolumn{2}{l|}{ Structurals } & \multicolumn{2}{l|}{ Collaborative work } \\
\hline & $\begin{array}{l}\text { Arrows(back } \\
\text { \& forward) }\end{array}$ & Printings & $\begin{array}{l}\text { On-line } \\
\text { help }\end{array}$ & $\begin{array}{l}\text { General } \\
\text { vision } \\
\text { maps }\end{array}$ & Filters & Chat & Forum & e-mail \\
\hline Active & $\sqrt{ }$ & $\sqrt{ }$ & & $\sqrt{ }$ & $\sqrt{ }$ & $\sqrt{ }$ & $\sqrt{ }$ & $\sqrt{ }$ \\
\hline Reflective & $\sqrt{ }$ & $\sqrt{ }$ & $\sqrt{ }$ & $\sqrt{ }$ & $\sqrt{ }$ & & & $\sqrt{ }$ \\
\hline Sensing & $\sqrt{ }$ & $\sqrt{ }$ & $\sqrt{ }$ & $\sqrt{ }$ & $\sqrt{ }$ & $\sqrt{ }$ & $\sqrt{ }$ & $\sqrt{ }$ \\
\hline Intuitive & $\sqrt{ }$ & $\sqrt{ }$ & $\sqrt{ }$ & $\sqrt{ }$ & $\sqrt{ }$ & $\sqrt{ }$ & $\sqrt{ }$ & $\sqrt{ }$ \\
\hline Visual & $\sqrt{ }$ & $\sqrt{ }$ & $\sqrt{ }$ & $\sqrt{ }$ & $\sqrt{ }$ & $\sqrt{ }$ & $\sqrt{ }$ & $\sqrt{ }$ \\
\hline Verbal & $\sqrt{ }$ & $\sqrt{ }$ & $\sqrt{ }$ & $\sqrt{ }$ & $\sqrt{ }$ & $\sqrt{ }$ & $\sqrt{ }$ & $\sqrt{ }$ \\
\hline Sequential & $\sqrt{ }$ & $\sqrt{ }$ & $\sqrt{ }$ & & & $\sqrt{ }$ & $\sqrt{ }$ & $\sqrt{ }$ \\
\hline Global & & & & $\sqrt{ }$ & $\sqrt{ }$ & $\sqrt{ }$ & $\sqrt{ }$ \\
\hline
\end{tabular}

The Teaching agent selects appropriate education strategies for the organization of the training resources based on info urged by the user agent.
The following figure4 outlines the ABDITS input output schema:

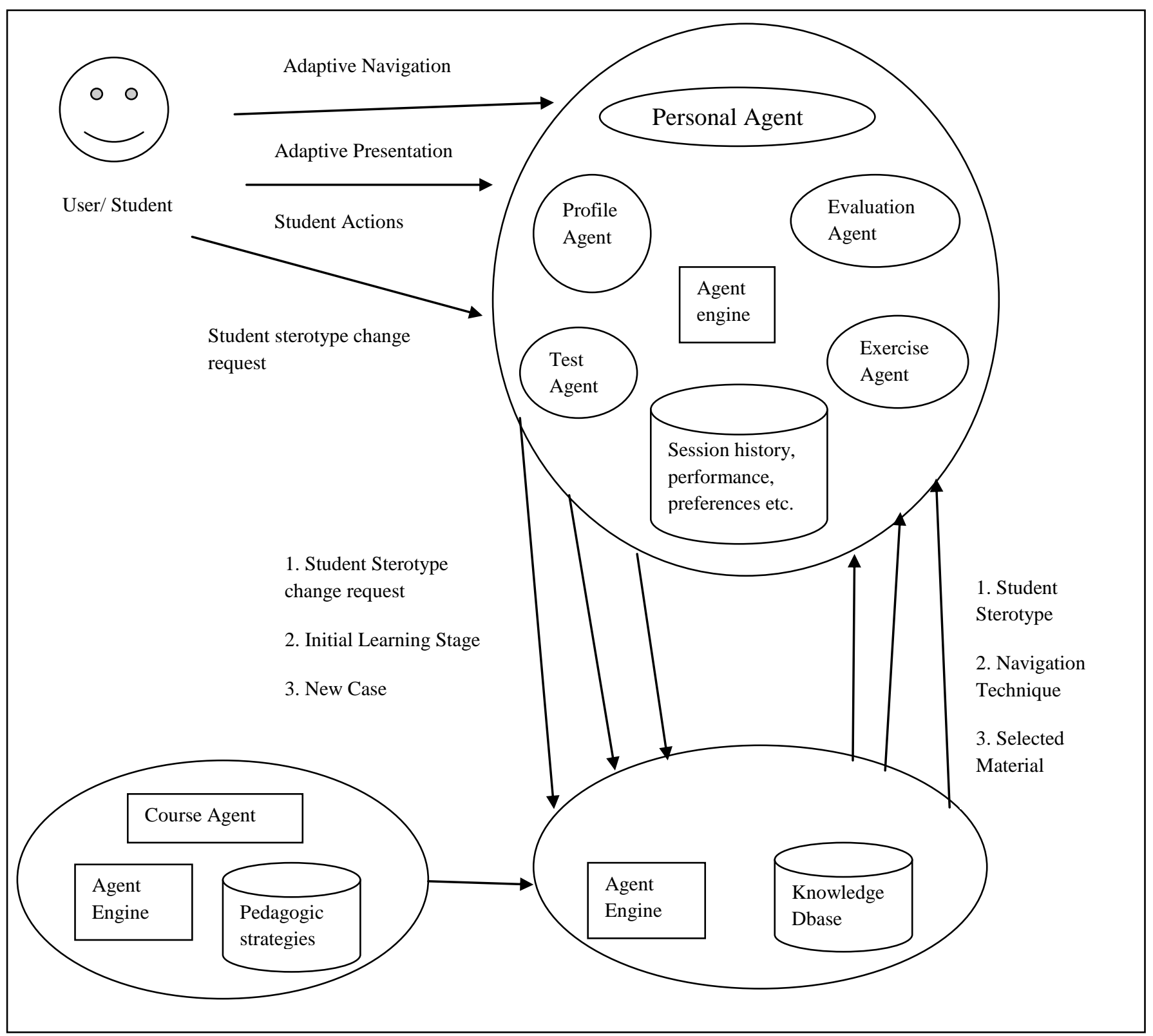

Figure 4: ABDITS Input/ Output Schema 


\section{CONCLUSIONS AND FUTURE SCOPES}

In this paper, try to delineate the utilization of intelligent agents to produce accommodative options to USD system, teaching and learning surroundings on the online. The proposed multi-agent system relies on two level agent architecture that Personal agent, Teaching Agent and Course Agent at higher level and Profile Agent, Evaluation Agent, Test Agent and Exercise Agent at lower level. Higher level agents realize continuous student help and tutoring throughout learning sessions. Lower level agents notice student modeling exploitation cosmic microwave background radiation techniques tailored from HabitatPro system by means that of student interaction considering learning designs. In this paper only student modeling is done. Tutor module would be done in near future.

\section{REFERENCES}

[1] Aamodt, A.; 2005, Knowledge Intesive Case-based reasoning and Intelligent tutoring system.

[2] Ang Yang, Ray Kemp, Kinshuk; 2001, Web based intelligent tutoring system.

[3] Brusilovsky, P. 1996. Methods and techniques of adaptive hypermedia. In User Modeling and UserAdapted Interaction, 87-129. Kluwer academic publishers.

[4] Brusilovsky, P. 1998. Adaptative educational systems on the world-wide-web: A review of available technologies. In Proceedings of Workshop WWW-Based Tutoring at Fourth International Conference on ITS (ITS'98). San Antonio, TX: Mit Press.

[5] B. Q. Pinto, C. R. Lopes, F. A. Dorça, M. A. Fernandes, "Intelligent Multiagent System for Distance Education Techinical Report", Department of Computing/Federal University of Uberlândia, Uberlândia, Brazil, 01/2002. (In Portuguese)

[6] B. Q. Pinto, C. R. Lopes, M. A. Fernandes, "Using the IEEE LTSC LOM Standard in Instructional Planning", Learning Technology publication of IEEE Computer Society, Volume 5 Issue 1, ISSN 1438-0625, January of 2003

[7] B. Queiroz, C. R. Lopes, M. A. Fernandes, "Automatic Curriculum Generation for a Web-Based Educational System", International Conference on Computers in Education (ICCE 2002), Auckland. Supplementary Proceedings. Palmerston: Massey University, 2002, pp. 26-28.

[8] Dent, L.; Boticario, J. G.; McDermott, J.; Mitchell, T. M.; and Zabowski, D. T. 1992. A personal learning apprentice. In Proceedings of the Tenth National Conference on Artificial Intelligence, 96-103. San Jose, CA: Mit Press.

[9] "Draft Standard for Learning Object Metadata", IEEE Learning Technology Standards Committee (LTSC), [database online], April 18 2001: [cited Jun. 12, 2002]. Available http://ltsc.ieee.org/doc/wg12/LOM_WD61_1.pdf
[10] Genesereth, M., and Fikes, R. 1992. Knowledge interchange format, version 3.0 reference manual. Technical Report KSL-92-86, Knowledge Systems Laboratory.

[11] G. Zlotkin and J. Rosenschein, ?Negotiation and task sharing among autonomous agents in cooperative domains,? in Proceedings of the Eleventh International Joint Conference on Artificial Intelligence, 1989, pp. 912이이․

[12] G. Weiss, editor. Multiagent Systems: A Modern Approach to Distributed Artificial Intelligence. The MIT Press, Cambridge, MA, 1999.

[13] H. Chalupsky et al., ?Electric elves: Agent technology for supporting human organizations, ? AI Magazine, Summer 2002.

[14] H. Shi, Y. Shang, A. Joshi, and M. Jurczyk. Laboratoryoriented teaching in web and distributed computing. In Proc. 2000 ASEE Annual Conference \& Exposition, St. Louis, June 2000.

[15] J. E. Beck and B. P. Woolf. Using a learning agent with a student model. In B. P. Goettl, H. M. Hal

[16] K. Sycara, M. Paolucci, M. van Velsen, and J. Giampapa, ?The RETSINA MAS infrastructure,? ? special joint issue of Autonomous Agents and MAS, vol. 7, no. 1 and 2, July 2003.

[17] M. Allouche, O. Boisser, and C. Sayettat, Temporal social reasoning in dynamic multi-agent systems, in Proceedings of the Fourth International Conference on Multi-Agent Systems (ICMAS-2000). IEEE Computer Society, 2000, pp. 23]28.

[18] M. K. Stern and B. P. Woolf. Curriculum sequencing in a Web-based tutor. In B. P. Goettl, H. M. Hal, C.L.Redeld, and V. J. Shute, editors, Intelligence Tutoring System (Proc. 4th Int'l Conf. ITS'98), pages 584\{593. Springer, 1998.

[19] N. Capuano, et al., "ABITS: An Agent Based Intelligent Tutoring System for Distance Learning", Proceedings of the International Workshop on Adaptive and Intelligent Web-based Educational Systems, Montreal, Canada, 2000.

[20] Y. Shang, C. Sapp, and H. Shi. An intelligent web representative. Information, 3(2):253-262, 2000.

[21] Y. Shang and H. Shi. A web-based multi-agent system for interpreting medical images. World Wide Web, 2(4):209\{218, 1999

[22] .M. R. Felder and L. Silverman, "Learning and Teaching Styles in Engineering Education", In Engineering Education 78(7), 1988, pp. 674-681.

[23] Habitat-ProTM Environment, Agents Inspired Technologies S.A, University of Girona, Girona, Spain, 2001.http://www.agentsinspired.com.

[24] Diagnostic instrument for the FSLSM model http://www2.ncsu.edu/unity/lockers/users/f/felder/public/ ILSdir/ilsweb.html 